\title{
Predictors of picture naming speed
}

\author{
F.-XAVIER ALARIO \\ Université René Descartes, Paris, France \\ LUDOVIC FERRAND \\ CNRS and Université René Descartes, Paris, France \\ MARINA LAGANARO \\ Université de Genève, Genève, Switzerland \\ BORIS NEW \\ Université René Descartes, Paris, France \\ ULI H. FRAUENFELDER \\ Université de Genève, Genève, Switzerland \\ and \\ JUAN SEGUI \\ CNRS and Université René Descartes, Paris, France
}

\begin{abstract}
We report the results of a large-scalepicture naming experiment in which we evaluated the potential contribution of nine theoretically relevant factors to naming latencies. The experiment included a large number of items and a large sample of participants. In order to make this experiment as similar as possible to classic picture naming experiments, participants were familiarized with the materials during a training session. Speeded naming latencies were determined by a software key on the basis of the digital recording of the responses. The effects of various variables on these latencies were assessed with multiple regression techniques, using a repeated measures design. The interpretation of the observed effects is discussed in relation to previous studies and current views on lexical access during speech production.
\end{abstract}

Articulating the name that corresponds to the picture of a common object is a fast, efficient, and relatively effortless cognitive skill. These aspects of naming performance obscure the complexity of the processes involved in this behavior (see Glaser, 1992; Johnson, Paivio, \& Clark, 1996). The aim of the present study was to investigate the representations and processes involved in picture naming by examining the individual contribution of nine predictors (e.g., printed frequency, age of acquisition, name agreement, etc.) to naming latencies. An attempt was made to locate the influence of each predictor in a standard model of picture naming.

In the present study, 388 pictures were named by 46 participants whose immediate naming latencies and delayed pronunciation latencies were measured. Similar studies have already been conducted in American English (Snodgrass \& Yuditsky, 1996), Welsh (Barry, Morrison, \& Ellis, 1997), British English (Ellis \& Morrison,

Part of the work reported in this article was presented at the 41 st Annual Meeting of the Psychonomic Society held in New Orleans, November 2000. Correspondence should be addressed to F.-X. Alario, now at Laboratoire de Psychologie Cognitive-Case 66, CNRS and Université de Provence, 3 place Victor Hugo, 13331 Marseille Cedex 3, France (e-mail: alario@up.univ-mrs.fr).
1998), Spanish (Cuetos, Ellis, \& Alvarez, 1999), Italian (Dell'Acqua, Lotto, \& Job, 2000), and even French (Bonin, Chalard, Méot, \& Fayol, 2002; Bonin, Peereman, Malardier, Méot, \& Chalard, 2003). ${ }^{1}$ Critically, the present study makes a number of methodological improvements over previous studies. First, we tested a larger number of pictures (388 pictures). Second, we started by familiarizing participants with the materials, as is commonly done in language production studies using the picture naming paradigm. This allowed us to assess the impact of the familiarization process on the effects that the different variables have on naming latencies. Third, we used a repeated measures design in the regression analysis, following the methodology advocated by Lorch and Meyers (1990; see below). Finally, we recorded the actual naming responses, which allowed us to check the accuracy of voice key measurements against the naming onset measured on the digital recording of the response. Together, these characteristics of the present study contribute to an increase in the amount of information gathered in the experiment as well as in the precision of its analysis. This directly improves the reliability of the effects that are reported.

According to current models of picture naming (e.g., Glaser, 1992; Humphreys, Riddoch, \& Quinlan, 1988; 
Levelt, Roelofs, \& Meyer, 1999), this basic task is accomplished by a sequence of at least four processesnamely, (1) activation of stored structural knowledge about the object's appearance, (2) activation of semantic information, (3) name retrieval, and (4) articulation (see Figure 1). We investigated the different processing stages by assessing the independent effects of the nine different predictors described below. The investigation of these potential effects can contribute to our understanding of the processes involved at each stage.

\section{Predictors of Picture Naming Speed}

In what follows, we will briefly discuss empirical findings related to predictors of picture naming speed. We will start with visual factors such as visual complexity and image agreement, then we will discuss semantic factors such as concept familiarity and imageability (or image variability), and then we will discuss lexical factors such as name agreement, frequency, and age of acquisition. We will finish with phonological factors such as number of phonemes and number of syllables.

Visual complexity refers to the number of lines and detail in the drawing. It is thought to determine the ease of
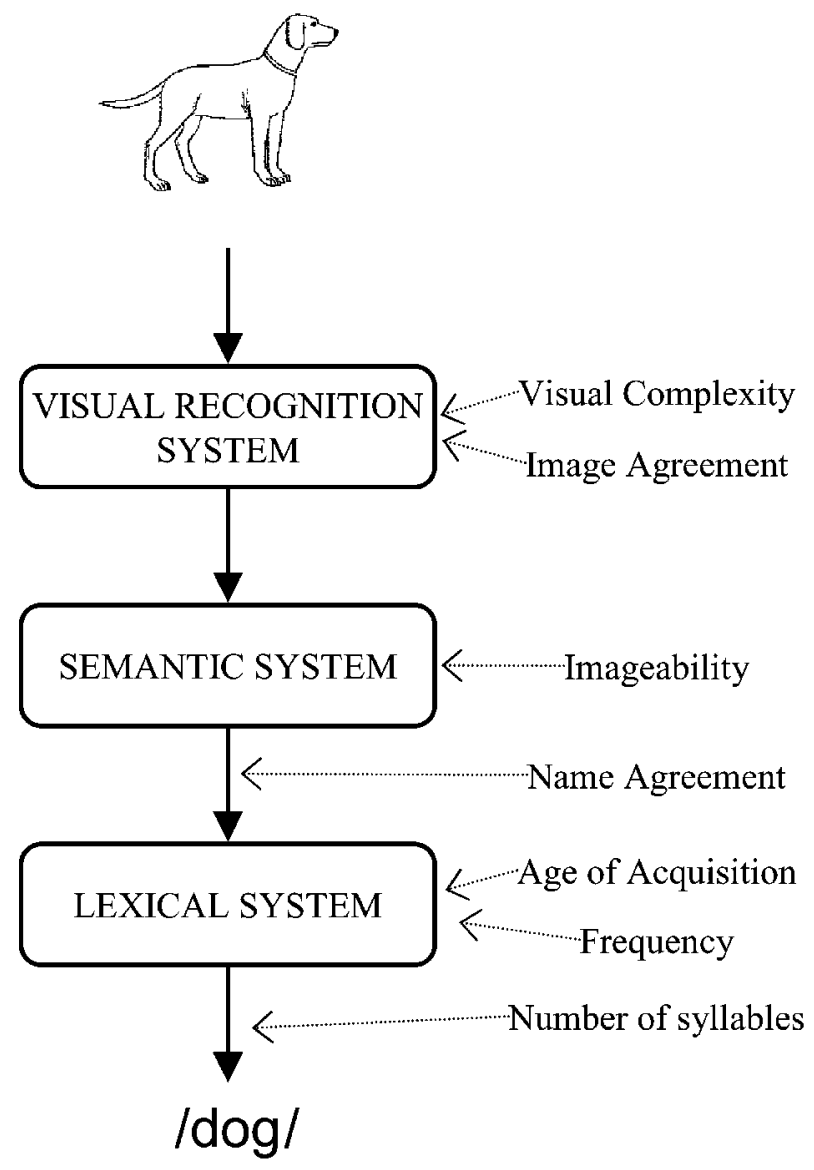

Figure 1. A general model of picture naming with suggested loci for the different variables investigated in this study. processing before or at the structural stage of object recognition. Visual complexity may affect such variables as naming latencies, tachistoscopic recognition thresholds, and memorizability. Early research that used pictorial stimuli established that more complex stimuli are more difficult to process than simple stimuli (Attneave, 1957; see also Ellis \& Morrison, 1998, for a recent replication). However, other investigators have shown that complex objects are identified and named as readily as simple objects (Biederman, 1987; Paivio, Clark, Digdon, $\&$ Bons, 1989). The most recent view is that this factor does not have a major impact on naming latencies for simple black-and-white drawings, such as those used here.

Image agreement refers to the degree to which the images generated by participants to a picture's name agree with the actual picture. It might be thought of as a measure of the match or mismatch between the picture and a stored canonical representation of the object. Barry et al. (1997) showed that pictures with higher ratings of image agreement were named faster than were those with lower ratings. These results suggest that image agreement has its influence at the level of object recognition, so that the closer a picture is to one's mental image of an object, the faster the naming time for that picture will be.

Imageability (or image variability) is a measure of the extent to which an object name evokes few or many different images for a particular object. Effects of imageability have been reported in patients with deep dyslexia who are thought to read exclusively by means of semantic representations (Plaut \& Shallice, 1993). Morrison, Ellis, and Quinlan (1992) failed to find a significant effect of imageability on picture naming speed. However, the range of imageability values used in this study was rather restricted. Using a wider range, Ellis and Morrison (1998) found a significant effect of that factor. Plaut and Shallice (1993) interpreted imageability in terms of number of semantic features, so that names with high imageability have "richer" semantic representations than do names with lower imageability. Under this interpretation, the sensitivity of the picture naming task to the imageability variable could be attributed to the fact that objects with high imageability names are easier to process at the semantic level (during object identification).

Concept familiarity refers to the familiarity of the depicted concept. Familiarity has been shown to have important effects on various memory and cognitive processing tasks. In particular, Ellis and Morrison (1998), Snodgrass and Yuditsky (1996), and Feyereisen, Van der Borght, and Seron (1988) showed that, in their experiments, rated familiarity was a significant predictor of picture naming latencies so that the more familiar a concept is, the faster the naming time for that item will be. Hirsh and Funnell (1995) reported that neuropsychological patients with progressive semantic dementia were able to name pictures with high concept familiarity better than those with low concept familiarity, even when other factors such as age of acquisition and frequency 
were taken into account. They suggested that concept familiarity for pictures is equivalent to frequency for words, and that concept familiarity affects the ease with which representations of pictures can activate their central semantic representations.

Name agreement (or codability) refers to the degree to which participants agree on the name of the picture. Name agreement is measured by assessing the number of different names given to a particular picture across participants. Pictures that elicit many different names have lower name agreement than do those that elicit a single name. This information is important for picture-name matching studies, recall memory studies, and recognition studies in which verbal encoding is manipulated. Name agreement is also a robust predictor of naming difficulty. Pictures with a single dominant response are named more quickly and accurately than those with multiple responses (Barry et al., 1997; Lachman, Shaffer, \& Hennrikus, 1974; Paivio et al., 1989; Snodgrass \& Yuditsky, 1996; Vitkovitch \& Tyrrell, 1995). More importantly, name agreement affects naming latencies independently of the effects of correlated attributes such as word frequency and rated age of name acquisition (Lachman et al., 1974; Vitkovitch \& Tyrrell, 1995).

Frequency is a measure of the degree of use of a given word, generally on the basis of counts of written corpora (e.g., Francis \& Kučera, 1982, in English; Content, Mousty, \& Radeau, 1990, or New, Pallier, Ferrand, \& Matos, 2001, in French). A strongly correlated predictor is age of acquisition, which is an evaluation of the moment in life at which a particular word was first learned (see the next paragraph). It has generally been observed that picture naming latencies decrease as name frequency increases (Barry et al., 1997; Ellis \& Morrison, 1998; Oldfield \& Wingfield, 1965).

Age of acquisition refers to the age at which the words are learned. This measure can be obtained by asking adults to estimate this age (Morrison \& Ellis, 1995; Morrison et al., 1992) or by the analysis of children's productions (both methods have been found to produce similar estimates; Ellis \& Morrison, 1998; Morrison, Chappell, $\&$ Ellis, 1997). Some authors have suggested that the general influence of word frequency on learning, memory, and perception could be attributed solely to this factor, and that frequency effects are not found when age of acquisition is properly controlled (Bonin et al., 2002; Carroll \& White, 1973; Morrison et al., 1997; Morrison et al., 1992). However, Barry et al. (1997), Snodgrass and Yuditsky (1996), and Ellis and Morrison (1998) found that the time taken to name a pictured object correctly was affected both by rated age of acquisition and by the frequency of the name (in accord with Lachman, 1973, and Lachman et al., 1974).

Number of syllables and number of phonemes are phonological factors. It is commonly assumed that the phonological encoding of a word involves filling a word frame with the different segments or syllables that compose that word (e.g., Fromkin, 1971; Shattuck-Hufnagel,
1979). The main evidence in support of this claim comes from speech errors, and particularly from the existence of cases in which words are produced with erroneous segments or segments are exchanged between words. This encoding description leads to the prediction that longer words take more time to be encoded than do short words, if either the retrieval or the encoding of the units is assumed to be sequential. Various studies have addressed the issue of the existence of a length effect in word production, but the results are inconsistent. For example, Klapp, Anderson, and Berrian (1973) found a small but significant difference between monosyllabic and bisyllabic words in a picture naming task. This result was recently replicated by Santiago, MacKay, Palma, and Rho (2000). Syllabic length effects were also found by Cuetos et al. (1999) in a study similar to the present one. However, Dell' Acqua et al. (2000) and Snodgrass and Yuditsky (1996) did not find the effect, nor did BachoudLévi, Dupoux, Cohen, and Mehler (1998) in a study involving various factorial design experiments.

As was noted previously, our experiment comprised two phases. First, there was a familiarization phase during which participants named all the pictures and received feedback on the names. The experiment proper was conducted during a second phase. We used this procedure because most psycholinguistic experiments that use the picture naming paradigm include familiarization of this type. In the presentation of the predictors used in our study, we have not included a systematic discussion of the impact of the familiarization phase on the effects of the different variables. Indeed, our primary interest lies on the second (postfamiliarization) naming session, whose results can be compared with those of other studies (e.g., language production studies). As a general prediction concerning the effects of familiarization on the participants' performance, one can expect that naming times will be shorter and less variable in the second than in the first session. Consequently, the effects of the manipulated factors will probably be somewhat attenuated. Besides this general point, it could be the case that the effect of a particular variable is specifically affected by the familiarization and the repetition of the items. In this study we did not have a priori hypotheses concerning this possibility for any particular variable.

\section{EXPERIMENT}

In order to evaluate the independent contribution of the nine variables included in the study to the process of single-word production, we conducted a large-scale picture naming experiment. The experiment we conducted comprised two sessions. During the first session, the participants named the pictures, which they had not seen before. The collected responses provided naming times without prior familiarization. Furthermore, in each trial of this session, the expected modal name of the picture was written on the computer screen after the naming response had been recorded. This feedback was intended 
to familiarize the participants with the picture names that they were asked to use in the second session. During the second session, the participants named each picture twice; first in a classic immediate naming procedure and then in a delayed pronunciation task. In each trial, the participants first named the picture as fast as possible upon its appearance on the screen (immediate naming). Shortly after, a prompt - a question mark - appeared on the screen and triggered the second production of the name of the picture (delayed pronunciation). In this article, we will concentrate on the immediate naming latencies obtained in the first (familiarization) phase and in the second phase. We conducted various multiple regression analyses on this data set. The inclusion of delayed repetition in the study was originally motivated to address issues about the peripheral process of articulation (Balota \& Chumbley, 1985; Forster \& Chambers, 1973; Monsell, Doyle, \& Haggard, 1989; Savage, Bradley, \& Forster, 1990) and will be described in detail elsewhere.

\section{Method}

\section{Stimuli}

Three hundred eighty-eight black-and-white pictures were selected from among the picture database of Cycowicz, Friedman, Rothstein, and Snodgrass (1997), which included the 260 pictures of Snodgrass and Vanderwart (1980). The full database comprised 400 pictures, but we excluded 12 of them that had the same modal name as a more common object in the corpus. For example, the picture of a verre a pied (wineglass) was excluded because it has the same modal name as the picture of a verre (glass). The pictures used, which have previously been normed in French by Alario and Ferrand (1999), span a wide range of values in each of the relevant dimensions under consideration (see Table 1). Pairwise correlations between these variables can be found in Table 2. Eighteen additional pictures were selected to be used as training and warm-up trials during the experiment. All pictures were presented as black outlines on a white screen in the center of the computer screen.

\section{Definitions of the Independent Variables}

The normed values of most of the variables used in the present study are those of Alario and Ferrand (1999). In this section, we recall briefly how the norms were collected in that study.

Visual complexity (from Alario \& Ferrand, 1999). Participants were asked to rate the complexity of the black-and-white drawings of objects. They were told that complexity is a measure of the amount of detail or the intricacy of the lines in a picture, and they rated each picture on a 5-point scale $(1$, drawing very simple, 5 , drawing very complex).

Image agreem ent (from Alario \& Ferrand, 1999). Participants were asked to judge how closely each picture resembled their mental image of the object by "comparing" their mental image of the object with the representation adopted in the pictorial stimuli. Participants rated the degree of agreement between their image and the picture by using the 5-point scale: A rating of 1 indicated low agreement, the picture provided a poor match to their image, and a rating of 5 indicated high agreement.

Imageability (from Alario \& Ferrand, 1999). Participants were instructed to rate on a 5-point scale $(1$, few images, 5 , many images) whether a given picture name evoked few or many different images for that particular object.

Concept familiarity (from Alario \& Ferrand, 1999). Participants rated the degree to which they come in contact with or think about the concept on a 5-point scale (1, a very unfamiliar object, 5 , a very familiar object).

Name agreem ent (from Alario \& Ferrand, 1999). Name agreement was evaluated by calculating the $H$ statistic on the naming outcomes in an off-line task. $H$ measures the dispersion of the responses provided; its value is zero if all participants provide the same name for the picture, and it increases with the number of different responses.

Printed frequency (from New et al., 2001). Frequency values were taken from the new French database LEXIQUE (New et al., 2001). The values used are expressed in terms of occurrences per million words. This recent corpus is based on texts published from 1950 to 2000 and contains 31 million words.

Age of acquisition (from Alario \& Ferrand, 1999). Participants were asked to estimate the age at which they thought they had learned each of the names in its written or oral form on a 5-point scale $(1$, learned at $0-3$ years, 5 , learned at age $12+$, with 3-year age bands in between).

Number of phonemes and syllables. These were taken from the French lexical database LEXIQUE (New et al., 2001).

\section{Participants}

Forty-six students at the University of Geneva, Switzerland, participated in the experiment for course credit. All were native speakers of French with normal or corrected-to-normal vision.

\section{Procedure}

The experiment was divided into two sessions that were run at an interval of 1 week. Each session lasted for about $1 \mathrm{~h}$ and included three pauses. During the first session, the participants were familiarized with the materials. In each experimental trial, they were asked to name as quickly as possible a picture that appeared on the screen. Their response was recorded during a 2,000-msec period. As soon as articulation started and the voice key was triggered, the

Table 1 Summary of the Nine Independent Variables Tested in the Experiment

\begin{tabular}{lccccccrr}
\hline \multicolumn{1}{c}{ Variable } & $M$ & $S D$ & Min & Percentile & Median & Percentile & Max & Skew \\
\hline Name agreement $(H)$ & 0.29 & 0.38 & 0.00 & 0.00 & 0.15 & 0.47 & 1.87 & 1.46 \\
Image agreement & 3.49 & 0.73 & 1.00 & 3.03 & 3.60 & 4.03 & 4.90 & -0.73 \\
Concept familiarity & 2.78 & 1.21 & 1.07 & 1.80 & 2.47 & 3.87 & 4.97 & 0.39 \\
Visual complexity & 3.09 & 0.93 & 1.00 & 2.38 & 3.10 & 3.76 & 5.00 & 0.00 \\
Imageability & 2.82 & 0.62 & 1.43 & 2.33 & 2.67 & 3.21 & 4.70 & 0.70 \\
Age of acquisition & 2.44 & 0.74 & 1.12 & 1.87 & 2.38 & 2.96 & 4.62 & 0.39 \\
Written frequency & 25.3 & 55.0 & 0 & 2 & 8 & 21 & 477 & 4.72 \\
Number of phonemes & 4.7 & 1.6 & 2 & 3 & 5 & 6 & 10 & 0.66 \\
Number of syllables & 1.9 & 0.7 & 1 & 1 & 2 & 2 & 4 & 0.54 \\
\hline
\end{tabular}

Note-This summary is based on the 329 items that were included in the regression analysis. 
Table 2

Pairwise Correlations Between the Predictors Used in This Study

\begin{tabular}{|c|c|c|c|c|c|c|c|c|}
\hline Predictors & NA & IA & Fam & V. Comp. & IV & AoA & W. Freq. & $\begin{array}{l}\text { Number of } \\
\text { Phonemes }\end{array}$ \\
\hline Name agreement $(H)$ & 1 & & & & & & & \\
\hline Image agreement & $-0.286^{*}$ & 1 & & & & & & \\
\hline Concept familiarity & -0.131 & -0.099 & 1 & & & & & \\
\hline Visual complexity & 0.083 & -0.007 & $-0.436^{*}$ & 1 & & & & \\
\hline Imageability & -0.188 & $-0.200 *$ & $0.610^{*}$ & $-0.248 *$ & 1 & & & \\
\hline Age of acquisition & $0.325 *$ & -0.032 & $-0.589 *$ & $0.254^{*}$ & $-0.623 *$ & 1 & & \\
\hline Written frequency & -0.085 & -0.056 & $0.432 *$ & -0.153 & $0.369 *$ & $-0.380^{*}$ & 1 & \\
\hline Number of phonemes & -0.024 & 0.091 & -0.128 & 0.144 & -0.139 & $0.292 *$ & $-0.219 *$ & 1 \\
\hline Number of syllables & -0.039 & 0.095 & -0.182 & 0.176 & -0.164 & $0.251 *$ & $-0.251 *$ & $0.817^{*}$ \\
\hline
\end{tabular}

Note-The data are based on the 329 items used in the multiple regression. Correlations significant to the .01 level, Bonferroni corrected, are marked with an asterisk. NA, name agreement; IA, image agreement; Fam, concept familiarity; V. Comp, visual complexity; IV, image variability (imageability); AoA, Age of acquisition; W. Freq, printed word frequency.

picture disappeared from the screen. It was replaced by the modal name of the picture written in capital letters. The participants were instructed to check their response against that provided by the computer and, if the two differed, to use only the name provided by the computer during the next session. The appearance of the following trial was self-paced. This feedback procedure was modeled from familiarization procedures used in previously reported picture naming experiments. Each experimental trial of the second session comprised an immediate naming and a delayed pronunciation response. The participants were asked to name the picture as quickly as possible when it appeared on the computer screen. Their response was recorded during a 2,000-msec period, although as soon as they started to articulate it, the target disappeared from the screen. A prompt (question mark) appeared $750 \mathrm{msec}$ after the end of the fixed recording period. The participants then had to repeat the picture name they had previously produced. Each session lasted for approximately $1 \mathrm{~h}$. The participants were given short breaks between blocks (see the Design section below).

The experiment was piloted by the program DMDX (Forster \& Forster, 2003). This program recorded a digital version of the participant's responses. It also provided naming times evaluated by a software voice key. In order to test the reliability of the voice key measurements, we selected 7 participants at random to conduct a comparative analysis of the response onset times obtained with the software voice-key and those obtained by visual inspection of the recorded waveform of the responses. The correlation between these two measures was always very high (all correlation coefficients $>.84$, all $r^{2} \mathrm{~s}>.71$ ), indicating a high degree of consistency between the two measures. In the analysis reported below, we always used the times provided by the software voice key.

\section{Design}

Every participant named all 388 pictures during both sessions. During the first (familiarization) session, the pictures were presented in a random order. For the second session, four pseudo-random lists were created, in which two consecutive items were neither semantically nor phonologically related. Each participant received one of the experimental lists. The experiment began with a practice block of four items. The 388 experimental items were then presented in four blocks of 97 items. The first four trials that started a block were warm-up trials.

\section{Results}

The following procedures were followed for the analysis of the two naming sessions. The data of the 46 par- ticipants were first screened for errors and outliers. We considered as errors and excluded those trials in which the voice key malfunctioned, those in which the participants stuttered, hesitated noisily, or gave an incorrect response, and trials in which naming latencies were more than three standard deviations from the mean of the participant (outliers). We also excluded from the analysis all items that led to less than $40 \%$ correct responses. We also excluded a few items (mainly compounds such as pomme de terre [potato]) that could not be found in the French database LEXIQUE (New et al., 2001). This left 329 items.

We conducted separated single-equation multiple regression analyses on the immediate naming latency data of the first and second sessions. The experimental design we used included repeated measures by participants. Most often picture naming studies that have analyzed this type of data sets have used response times averaged over subjects (see the references cited earlier). This method yields one data point per item on which the regression is conducted. The problem with this averaging procedure is that by reducing all data points for a given item to a single measure, it loses valuable information in the original data set. In particular, the averaging does not allow us to partial out any participant effect (Lorch \& Myers, 1990). In our analysis of the data set, no averaging was done: The regression was conducted directly on the individual naming latencies $(46 \times 329=$ 15,134 data points, from which errors and outliers were excluded). The variables included in the analysis were the nine factors described earlier, in addition to participants coded as dummy variables. ${ }^{2}$ Owing to the high number of degrees of freedom and of tests conducted in these analyses, we adopted an $\alpha$ criterion of 0.01 .

\section{First Session}

The average naming latency was $883 \mathrm{msec}$, with a standard deviation of $289 \mathrm{msec}$. There were errors or outliers on $27 \%$ of the trials $(4,079$ out of 15,134$)$. The overall regression equation was significant, and the 
model accounted for $27 \%$ of the variance in the data $\left[F(54,11000)=76.6, \operatorname{root} M S_{\mathrm{e}}=247.4, p<.001 ; R^{2}=\right.$ .27]. The results show that the following factors made significant independent contributions toward predicting naming speed: name agreement $(p<.001)$, image agreement $(p<.001)$, familiarity $(p<.01)$, imageability $(p<.001)$, age of acquisition $(p<.001)$, and printed frequency $(p<.001)$. There was no significant contribution of visual complexity ( $p=.58$ ). Number of syllables was not significant ( $p=.58$ ), and number of phonemes was marginally significant $(p=.04)$. Note, however, that these two variables have a high correlation between them. If only one of them was included in the analysis, then its effect was significant (number of syllables, $p<$ .01 , or number of phonemes, $p<.01$ ). This observation suggests that the length of the items influenced naming latencies in this task, although its effect was weak.

\section{Second Session}

The average naming latency was $844 \mathrm{msec}$, with a standard deviation by participants of $255 \mathrm{msec}$. There were errors or outliers on $16 \%$ of the trials $(2,417$ out of $15,134)$. The improvement of performance between the first and the second naming session was shown to be significant by participants and by items [naming latencies, $t_{1}(45)=4.46, p<.01$, and $t_{2}(328)=14.2, p<.01$; error rates, $t_{1}(45)=6.68, p<.01$, and $t_{2}(328)=18.7, p<$ $.01]$. Table 3 shows the results of the simultaneous multiple regression analysis on the immediate naming data. The overall regression equation was significant, and the model accounted for $29 \%$ of the variance in the data $\left[F(54,12662)=96.15\right.$, root $M S_{\mathrm{e}}=215.5, p<.001$; $\left.R^{2}=.29\right]$. The results show that name agreement $(H)$, image agreement, visual complexity, imageability, age of acquisition, and printed frequency made significant independent contributions toward predicting naming speed. Number of syllables was significant. The $\beta$ coefficients for concept familiarity and number of phonemes were not significant.

\section{Further Analysis of the Second Session Data}

All but one of the reported effects were in the expected direction. For example, the significant positive $\beta$ coeffi-

Table 3

Simultaneous Multiple Regression Analysis on the Picture Naming Latencies, Second Session (After Familiarization)

\begin{tabular}{lcccc}
\hline \multicolumn{1}{c}{ Predictor } & \multicolumn{3}{c}{ Standard } & \\
\hline Name agreement & 121.4 & 6.05 & 20.1 & .000 \\
Image agreement & -33.3 & 2.83 & -11.8 & .000 \\
Concept familiarity & -.91 & 2.28 & -.40 & .688 \\
Visual complexity & 7.27 & 2.24 & 3.25 & .001 \\
Imageability & -52.3 & 4.31 & -12.1 & .000 \\
Age of acquisition & 69.4 & 3.70 & 18.8 & .000 \\
Printed frequency & -.19 & .038 & -4.97 & .000 \\
Number of phonemes & -.73 & 2.12 & .34 & .731 \\
Number of syllables & -12.2 & 4.53 & -2.70 & .007 \\
\hline
\end{tabular}

cient for the age of acquisition indicates that pictures with names acquired later produced longer naming latencies than did pictures with names learned earlier. Somewhat surprisingly, the marginally significant $\beta$ coefficient reported for the number of syllables predictor was negative. Under a standard interpretation, this would indicate faster naming times for longer words-a counterintuitive result. This effect was similarly observed whether the variable that is most highly correlated to the number of syllables (the number of phonemes) was included in the analysis or not, suggesting that the counterintuitive $\beta$ coefficient cannot be readily attributed to colinearity between the predictors. Furthermore, we conducted a post hoc exploration of the effect of syllabic length by randomly selecting 60 pictures, 20 with monosyllabic names, 20 with bisyllabic names, and 20 with trisyllabic names. These three groups of items were matched for nearly all other dimensions available in our study [all $F_{\mathrm{s}}<1$ but for the predictors name agreement for which $F(2,57)=1.21, p=.31$, and image complexity for which $F(2,56)=1.51, p=.23$ ]. The three groups of pictures could not be matched for length in phonemes while matching for the other factors (on average, pictures with monosyllabic names had 3.0 phonemes, those with bisyllabic names had 4.5 phonemes, and those with trisyllabic names had 6.5 phonemes). The analysis of these data showed the following naming times for the three groups: monosyllabic, $841 \mathrm{msec}$; bisyllabic, $841 \mathrm{msec}$; trisyllabic, $821 \mathrm{msec}$. These results suggest that the length effect might be limited to a (still counterintuitive) faster naming for trisyllabic items $\left[F_{1}(2,90)=2.49, p=.09\right.$; $\left.F_{2}(2,57)<1\right]$. This unexpected outcome will be discussed further in the General Discussion section.

The effect of the training session can be assessed by comparing the pattern of results in the first and second naming sessions. It can also be assessed by comparing, within the second session, naming times for items that were successfully named in the first session and naming times for items for which an incorrect response was provided in the first session. Note that most of the responses in the first session were correct; therefore, there are many more data points in the first subset (first session correct, 10,590 data points) than in the second subset (second session correct, 2,785 data points). The post hoc analysis of this second set must therefore be interpreted carefully. The analyses revealed that the pattern of performance on the actual naming session (Session 2) was not critically influenced by the nature of the response in the first session. In other words, multiple regression analysis yielded similar levels of significant $\beta$ coefficients of similar signs for the different predictors. Overall, $\beta$ coefficients and $t$ values were smaller in the second subset than in the whole data set, probably because of the smaller number of data. The only notable difference between the two data sets concerns the predictors that index item length (in phonemes and in syllables). Whereas only syllabic length contributed (marginally) to predicting naming latencies in the first subset, both length in sylla- 
bles and phonemes (marginally) contributed to the prediction of naming latencies in Subset 2 (see the General Discussion section for details about the interpretation of length effects).

\section{Comparison of the Naming Data With Previous Studies}

In order to tease apart the independent contribution to naming latencies of different closely related factors, we included in this study a large number of items named by many participants. Although this high number of observations argues for the robustness of the effects we report, it remains important to compare our results with those of previous studies.

Table 4 provides a summary of the multiple regression analysis results obtained in the present study (conducted in French) as well as in other studies conducted in American English (Snodgrass \& Yuditsky, 1996), Welsh (Barry et al., 1997), British English (Ellis \& Morrison, 1998), Spanish (Cuetos et al., 1999), Italian (Dell'Acqua et al., 2000), and French (Bonin et al., 2002; Bonin et al., 2003). As can be seen, frequency, age of acquisition, name agreement, and image agreement emerged as the most robust predictors of picture naming speed across the eight studies considered. The other effects contributed significantly only in a fraction of the reported studies, although not all studies investigated all effects.

A notable difference between the results of the present study and those of the study conducted in French by Bonin et al. (2002) is that we found a clear effect of frequency, whereas Bonin et al. failed to find such an effect (although see Bonin et al., 2003). This difference in the results is of importance in the current debate about the relationship between frequency and age-of-acquisition effects. One of the various minor differences between their study and ours could be responsible for this difference: for example, the fact that the two studies used different frequency counts, or the difference in the number of items (203 in their analysis, 329 in ours). Because the original collection of pictures used in both studies was the same, we were able to make a direct comparison between the data collected in the two studies by conducting various post hoc regression analyses on our data. In these analysis, we included only the items used by Bonin et al. (2002), and we used as predictors those tested in their study. We conducted four different analyses, which differed in the frequency count used: LEXIQUE frequency (New et al., 2001), $\log ($ LEXIQUE + 1), BRULEX frequency (Content et al., 1990), and $\log ($ BRULEX + 1). In all these analyses, we found significant effects of the frequency factor (all $p$ s $<.01$ ). Although we cannot be sure why Bonin et al. (2002) did not find an effect of frequency, we can be confident that frequency contributed significantly as a robust predictor of naming latency in our experiment, even when the potential contributions of age of acquisition and concept familiarity were partialed out (thus confirming the results obtained by Barry et al., 1997; Ellis \& Morrison, 1998; Snodgrass \& Yuditsky, 1996; and the more recent results reported by Bonin et al., 2002).

\section{GENERAL DISCUSSION}

In this study, we investigated the cognitive processes involved in the picture naming task by assessing the independent roles of different predictor variables on picture naming latencies. We improved on a methodology introduced in previous studies by familiarizing participants with the experimental materials, by using a very large sample of data, and by analyzing it in a repeated measures, multiple regression analysis. Naming latencies were measured by a software voice key. These measurements were shown to be reliably similar to the measurements obtained by analyzing the actual acoustic onset on the digital recordings of the responses. These characteristics of our study argue in favor of the reliability of the reported effects.

Table 4

Summary Table of the Multiple Regression Results Obtained in the Present Study (in French) and in Studies Conducted in American English (Snodgrass \& Yuditsky, 1996), in Welsh (Barry et al., 1997), in British English (Ellis \& Morrison, 1998), in Spanish (Cuetos et al., 1999), in Italian (Dell'Acqua et al., 2000), and Two Other Studies Conducted in French (Bonin et al., 2002; Bonin et al., 2003)

\begin{tabular}{lcccccccc}
\hline \multicolumn{1}{c}{ Language } & This Study & American & Welsh & British & Spanish & Italian ${ }^{1}$ & French $1^{1}$ & French2 \\
\hline Frequency & $N=329$ & $N=250$ & $N=195$ & $N=220$ & $N=140$ & $N=266$ & $N=203$ & $N=299$ \\
Age of acquisition & $\checkmark$ & $\checkmark$ & $\checkmark$ & $\checkmark$ & $\checkmark$ & n.s. & n.s. & $\checkmark$ \\
Name agreement & $\checkmark$ & $\checkmark$ & $\checkmark$ & $\checkmark$ & $\checkmark$ & $\checkmark$ & $\checkmark$ & $\checkmark$ \\
Image agreement & $\checkmark$ & $\checkmark$ & $\checkmark$ & $\checkmark$ & $\checkmark$ & $\checkmark$ & $\checkmark$ & $\checkmark$ \\
Imageability & $\checkmark$ & - & $\checkmark$ & - & $\checkmark$ & - & $\checkmark$ & $\checkmark$ \\
Number of syllables & $\checkmark 2$ & n.s. & - & $\checkmark$ & - & - & $\checkmark$ & n.s. \\
Number of phonemes & n.s. & $\checkmark$ & n.s. & n.s. & $\checkmark$ & - & n.s. & n.s. \\
Number of letters & - & n.s. & - & - & - & n.s. & n.s. & - \\
Concept familiarity & n.s. & $\checkmark$ & n.s. & $\checkmark$ & $\checkmark$ & n.s. & n.s. & n.s. \\
Visual complexity & $\checkmark$ & n.s. & n.s. & $\checkmark$ & n.s. & - & n.s. & n.s. \\
\hline
\end{tabular}

Note- $\checkmark$, significant effect; -, not available; n.s., effect not significant. ${ }^{1}$ Contrary to the other studies, these pictures were not taken from Snodgrass and Vanderwart (1980) or from Cycowicz et al. (1997). ${ }^{2}$ This effect was in the unexpected direction (negative $\beta$ coefficient). 
A first point that our research helps to establish is the impact of the familiarization phase on performance in a psycholinguistic picture naming experiment. The data sets obtained in the two naming phases were very comparable. Although the significance level of the reported effects is somewhat lower in the second session, the same overall pattern is observed in the two sessions. The major difference between the data sets of the first and the second session concerns the average naming latencies and their variability, as well as on the number of errors. ${ }^{3}$ As could be expected, performance was better in the second session, with an overall priming effect of $39 \mathrm{msec}$ on naming latencies and of $11 \%$ on error rates. The values of the standard deviations computed on the naming latencies data set showed less variability in the second than in the first session (first session, $289 \mathrm{msec}$; second session, $255 \mathrm{msec}$ ). Furthermore, a separate analysis of second naming trials for which the corresponding response in the familiarization phase (same item, same participant) was correct versus incorrect revealed no relevant differences. These expected results provide a clear motivation for the current practice of familiarizing participants with experimental materials before conducting a picture naming experiment. The resulting data set is more homogeneous, without a major influence on effects of the size reported here.

In the following section, we will briefly discuss the implications of the major effects that we observed in relation to previous studies and current views on lexical access during speech production.

\section{Visual Complexity and Image Agreement}

Visual complexity was a significant predictor of picture naming speed in the second naming session, a result also obtained by Ellis and Morrison (1998). These authors have suggested that the complexity of a drawing influences the time taken to recognize the image as the representation of a familiar object. However, many immediate naming studies have failed to find such an effect (Barry et al., 1997; Bonin et al., 2002; Bonin et al., 2003; Cuetos et al., 1999; Snodgrass \& Yuditsky, 1996). This absence of an effect is consistent with the view that this factor does not have a major impact on naming latencies for simple black-andwhite drawings such as those used here (Biederman, 1987; Paivio, Clark, Digdon, \& Bons, 1989).

Image agreement was a significant predictor of picture naming speed, indicating that pictures with higher ratings of image agreement were named faster than those with lower ratings. Barry et al. (1997) suggested that this variable relates to the ease with which a particular drawing is recognized as a positive instance of the object for which the entry level representation is established. They further suggested that image agreement has its influence relatively early during picture naming at the level of the stored structural descriptions. Processing at this level would be faster for items whose pictures closely resemble the stored structural description than for items whose pictures fit more poorly with its stored representation.

\section{Imageability and Concept Familiarity}

Imageability contributed significantly to naming latencies in the present study (see also Bonin et al., 2002; Ellis \& Morrison, 1998). The presence of an imageability effect is particularly notable given the restricted range of values available in this type of study, since the words used are all names of concrete objects. Ellis and Morrison (1998) suggested a semantic locus for this effectthat is, the meaning of a picture to be named becoming available faster the more imageable the object is.

Concept familiarity was not significant in the experimental session of the present study, although it had a significant effect during the familiarization phase. The effect of this factor has been reported only in three of the eight studies summarized on Table 4 (it was obtained by Cuetos et al., 1999; Ellis \& Morrison, 1998; Snodgrass \& Yuditsky, 1996). The lack of robustness of the familiarity effect with repetition and its observation only in some of the studies reported in the literature suggests that this variable has at most a weak effect on picture naming latencies. Concept familiarity is defined as a measure of the frequency with which participants use or encounter a given object. The absence of a familiarity effect could therefore suggest that the process of object identification involved in picture naming is not very sensitive to frequency of occurrence (as we will see below, the process of word retrieval seems sensitive to frequency of use).

\section{Name Agreement}

Replicating robust effects observed in previous studies (e.g., Barry et al., 1997; Bonin et al., 2002; Bonin et al., 2003; Cuetos et al., 1999; Dell' Acqua et al., 2000; Ellis \& Morrison, 1998; Lachman et al., 1974; Paivio et al., 1989; Snodgrass \& Yuditsky, 1996; Vitkovitch \& Tyrrell, 1995), we found that the factor name agreement emerged as the strongest predictor of picture naming latencies. This effect was found despite the fact that in our study participants benefited from a first phase of familiarization with the pictures, in which they were given the opportunity to identify and study the names of the experimental pictures. This effect signals the importance of the "strength" of the relationship between a given depicted concept and its corresponding name. Presumably, processing objects with low name agreement produces the activation of more lexical candidates than does the processing of objects with high name agreement. The effect of name agreement would reflect the competition between alternative responses and additional time required to select between them. Other studies have found that name agreement decreased naming but not object decision reaction times for the same pictures, suggesting that it affected a postidentification stage unique to naming (name retrieval, response generation, or both; Johnson et al., 1996).

\section{Frequency and Age of Acquisition}

These two predictors are highly correlated and have triggered important discussions in the field of psycho- 
linguistics. Various studies have tried to determine whether one is responsible for the effect attributed to the other. Some studies of picture naming found effects of age of acquisition but not frequency on picture naming speed (e.g., Gilhooly \& Gilhooly, 1979; Morrison et al., 1992). However, more recent investigations involving larger numbers of items and more up-to-date frequency measures have tended to find independent contributions of both variables (e.g., Barry et al., 1997; Ellis \& Morrison, 1998; Snodgrass \& Yuditsky, 1996). Thus, the object pictures that are named the fastest are acquired early and of high frequency of use, whereas those that are named slowest are acquired late and are of low frequency. In the present study, we observed clear effects of both printed frequency and age of acquisition. Therefore, the results we report clearly indicate that both frequency and age of acquisition play independent determinant roles in picture naming (but see Bonin et al., 2002; Bonin et al., 2003).

It has also been shown that the age-of-acquisition factor does not affect object classification speed (Morrison et al., 1992). This suggests that the effect of age of acquisition is located at the level of name retrieval itself. Barry et al. (1997) proposed that both frequency and age of acquisition affect the same essential process - namely, how a word's phonological representation is activated for its production in speech. They suggested that frequency and age of acquisition have their effect after the semantic level but prior to the articulation level: the level of name retrieval or the phonological encoding level (see Figure 1). This view is somehow strengthened by the fact that we did not observe an independent effect for concept familiarity in the second session of our experiment and by the fact that concept familiarity is not a robust predictor of naming latencies across studies. If concept familiarity is taken as a measure of object use frequency-as opposed to word use frequency - the absence of an effect of familiarity suggests that in this type of experiment the process that is sensitive to the frequency of use dimension is word retrieval rather than object identification.

\section{Number of Phonemes and Syllables}

Number of phonemes did not contribute significantly to predicting naming latencies. This absence of effect was also observed in most studies examining this variable (see Table 4). Number of syllables contributed marginally to naming latencies. However, this effect was not in the expected direction. The negative $\beta$ coefficient indicates shorter naming latencies for longer words. A post hoc analysis conducted on a subset of the items showed that trisyllabic items were named, on average, faster than mono- or bisyllabic items. We can consider this result in light of previous attempts to demonstrate effects of the number of syllables. In studies similar to this one, Cuetos et al. (1999) found the effect, but Snodgrass and Yuditsky (1996) and Dell'Acqua et al. (2000) failed to find them (see Table 4). As was mentioned in the introduction, the effect of the number of syllables has proved elusive in picture naming experiments (compare Bachoud-
Lévi et al., 1998, with Santiago et al., 2000). This does not mean that length in syllables does not affect any level of processing during picture naming or that syllables play no significant role during phonological encoding. It could be that certain specific conditions have to be met for the effect to be observed. Recent evidence provided by Meyer, Roelofs, and Levelt (2003) suggests such a conclusion. These authors found effects of the number of syllables in blocked designs (i.e., when the number of syllables of a given experimental block was held constant) but not in mixed designs. Another possibility is that the syllable length effect interacts with printed frequency, so that the effect is observed only for low frequency names but not for high frequency names (see Ferrand, 2000, for such a result obtained in a word naming task). Clearly, further investigation of this potentially important effect is required. Indeed, the results observed for this latter factor provide an example of the limitations of the methodology used here, in which experimental factors are not explicitly manipulated.

\section{CONCLUSION}

The processes involved in the production of the name of a picture are sensitive to a variety of factors. Our study provides converging and new evidence on these effects. On the methodological side, the present study has shown the reliability of naming latency measurements obtained with a software voice key. It also provides an example of the application of a repeated measures design in a multiple regression analysis, a recommended methodology that is seldom used for this type of experiment.

The main conclusions that can be drawn from our study are as follows. Visual complexity, image agreement, and name agreement are major determinants of naming speed. Frequency and age of acquisition both make independent contributions to naming times. This conclusion is different from that reached in some other studies in which frequency effects disappeared when age of acquisition was controlled for. Also, the reliable effect observed for word frequency contrasts with the absence of an effect of the object familiarity factor, which could be taken as a measure of frequency of object use. Finally, our results indicate that the nature of the effect of word length still requires a more thorough study.

\section{REFERENCES}

ALARIO,F.-X., \& FERRAND, L. (1999). A set of 400 pictures standardized for French: Norms for name agreement, image agreement, familiarity, visual complexity, image variability, and age of acquisition. Behavior Research Methods, Instruments, \& Computers, 31, 531-552.

Attneave, F. (1957). Physical determinants of the judged complexity of shapes. Journal of Experimental Psychology, 53, 221-227.

Bachoud-Lévi, A.-C., Dupoux, E., Cohen, L., \& Mehler, J. (1998). Where is the length effect? A cross-linguistic study of speech production. Journal of Memory \& Language, 39, 331-346.

Balota, D. A., \& Chumbley, J. I. (1985). The locus of word frequency effects in the pronunciation task: Lexical access and/or production? Journal of Memory \& Language, 24, 89-106. 
BARrY, C., Morrison, C. M., \& Ellis, A. W. (1997). Naming the Snodgrass and Vanderwart pictures: Effects of age of acquisition, frequency, and name agreement. Quarterly Journal of Experimental Psychology, 50A, 560-585.

BIEDERMAN, I. (1987). Recognition-by-components: A theory of human image understanding. Psychological Review, 94, 115-147.

Bonin, P., Chalard, M., MÉot, A., \& FAYOL, M. (2002). The determinants of spoken and written picture naming latencies. British Journal of Psychology, 93, 89-114.

Bonin, P., Peereman, R., Malardier, N., Méot, A., \& Chalard, M. (2003). A new set of 299 pictures for psycholinguistic studies: French norms for name agreement, image agreement, conceptual familiarity, visual complexity, image variability, age of acquisition, and naming latencies. Behavior Research Methods, Instruments, \& Computers 35, 158-167.

CARRoll, J. B., \& White, M. N. (1973). Age-of-acquisition norms for 220 picturable nouns. Journal of Verbal Learning \& Verbal Behavior, 12, 563-576.

Content, A., Mousty, P. \& RAdEAU, M. (1990). BRULEX: Une base de données lexicales informatisée pour le français écrit et parlé [Brulex: A computerized lexical database for the French language]. L'Année Psychologique, 90, 551-566.

Cuetos, F., Ellis, A. W., \& Alvarez, B. (1999). Naming times for the Snodgrass and Vanderwart pictures in Spanish. Behavior Research Methods, Instruments, \& Computers, 31, 650-658.

Cycowicz, Y. M., Friedman, D., Rothstein, M., \& SNodgrass, J. G. (1997). Picture naming by young children: Norms for name agreement, familiarity, and visual complexity. Journal of Experimental Child Psychology, 65, 171-237.

Dell'Acqua, R., LotTo, L., \& Job, R. (2000). Naming times and standardized norms for the Italian PD/DPSS set of 266 pictures: Direct comparisons with American, English, French, and Spanish published databases. Behavior Research Methods, Instruments, \& Computers, 32, 588-615.

Ellis, A. W., \& Morrison, C. M. (1998). Real age-of-acquisition effects in lexical retrieval. Journal of Experimental Psychology: Learning, Memory, \& Cognition, 24, 515-523.

FERRAND, L. (2000). Reading aloud polysyllabic words and nonwords: The syllabic length effect reexamined. Psychonomic Bulletin \& Review, 7, 142-148.

Feyereisen, P., VAN Der Borght, F., \& SERon, X. (1988). The operativity effect in naming: A re-analysis. Neuropsychologia, 26, 401-415.

FORSTER, K. I., \& CHAMBERS, S. M. (1973). Lexical access and naming time. Journal of Verbal Learning \& Verbal Behavior, 12, 627-635.

Forster, K. I., \& Forster, J. C. (2003). DMDX: A Windows display program with millisecond accuracy. Behavior Research Methods, Instruments, \& Computers, 35, 116-124.

FRANCIS, W. N., \& KUČERA, H. (1982). Frequency analysis of English usage: Lexicon and grammar. Boston: Houghton Mifflin.

FromkIN, V. A. (1971). The non-anomalous nature of anomalous utterances. Language, 47, 27-52

Gilhooly, K. J., \& GIL Hooly, M. L. (1979). Age-of-acquisition effects in lexical and episodic memory tasks. Memory \& Cognition, 7, 214-223.

Glaser, W. R. (1992). Picture naming. Cognition, 42, 61-105.

Hirsh, K. W., \& FunNell, E. (1995). Those old, familiar things: Age of acquisition, familiarity and lexical access in progressive aphasia. Journal of Neurolinguistics, 9, 23-32.

HumPhrEYs, G. W., RidDOCH, M. J., \& Quinlan, P. T. (1988). Cascade processes in picture identification. Cognitive Neuropsychology, 5, 67-103.

Johnson, C. J., PAivio, A., \& Clark, J. M. (1996). Cognitive components of picture naming. Psychological Bulletin, 120, 113-139.

Klapp, S. T., ANderson, W. G., \& Berrian, R. W. (1973). Implicit speech in reading reconsidered. Journal of Experimental Psychology, 100, 368-374.

LACHMAN, R. (1973). Uncertainty effects on time to access the internal lexicon. Journal of Experimental Psychology, 99, 199-208.

LACHMAN, R., ShafFer, J. P., \& HenNRikus, D. (1974). Language and cognition: Effects of stimulus codability, name-word frequency, and age of acquisition on lexical reaction time. Journal of Verbal Learning \& Verbal Behavior, 13, 613-625.

Levelt, W., Roelofs, A., \& Meyer, A. (1999). A theory of lexical access in speech production. Behavioral \& Brain Sciences, 22, 1-75. LORCH, R. F., \& MYERS, J. L. (1990). Regression analyses of repeated measures data in cognitive research. Journal of Experimental Psychology: Learning, Memory, \& Cognition, 16, 149-157.

Meyer, A. S., Roelofs, A., \& Levelt, W. J. M. (2003). Word length effects in object naming: The role of a response criterion. Journal of Memory \& Language, 48, 131-147.

Monsell, S., Doyle, M. C., \& Haggard, P. N. (1989). Effects of frequency on visual word recognition tasks: Where are they? Journal of Experimental Psychology: General, 118, 42-71.

Morrison, C. M., ChAPPELl, T. D., \& Ellis, A. W. (1997). Age of acquisition norms for a large set of object names and their relation to adult estimates and other variables. Quarterly Journal of Experimental Psychology, 50A, 528-559.

Morrison, C. M., \& Ellis, A. W. (1995). The roles of word frequency and age of acquisition in word naming and lexical decision. Journal of Experimental Psychology: Learning, Memory, \& Cognition, 21, 116-133.

Morrison, C. M., Ellis, A. W., \& Quinlan, P. T. (1992). Age of acquisition, not word frequency, affects object naming, not object recognition. Memory \& Cognition, 20, 705-714.

New, B., Pallier, C., Ferrand, L., \& Matos, R. (2001). Une base de données lexicales du français contemporain sur Internet: LEXIQUE [A lexical database of contemporary French on Internet: LEXIQUE]. L'Année Psychologique, 101, 447-462. Available at http://www. lexique.org.

OLDFIELD, R. C., \& WINGFIELD, A. (1965). Response latencies in naming objects. Quarterly Journal of Experimental Psychology, 17, 273-281. Paivio, A., Clark, J. M., Digdon, N., \& Bons, T. (1989). Referential processing: Reciprocity and correlates of naming and imaging. Memory \& Cognition, 17, 163-174.

Plaut, D. C., \& Shallice, T. (1993). Deep dyslexia: A case study of connectionist neuropsychology. Cognitive Neuropsychology, 10, 377-500.

Santiago, J., Mackay, D. G., Palma, A., \& Rho, C. (2000). Sequential activation processes in producing words and syllables: Evidence from picture naming. Language \& Cognitive Processes, 15, 1-44.

Savage, G. R., Bradley, D. C., \& Forster, K. I. (1990). Word frequency and the pronunciation task: The contribution of articulatory fluency. Language \& Cognitive Processes, 5, 203-326.

SHATTUCK-HuFNAGEL, S. (1979). Speech errors as evidence for a serialordering mechanism in sentence production. In W. E. Cooper \& E. C. T. Walker (Eds.), Sentence processing: Psycholinguistic studies presented to Merrill Garrett (pp. 295-342). Hillsdale, NJ: Erlbaum.

SNODGRASS, J. G., \& VANDERWART, M. (1980). A standardized set of 260 pictures: Norms for name agreement, image agreement, familiarity, and visual complexity. Journal of Experimental Psychology: Human Learning \& Memory, 6, 174-215.

SNODGRAss, J. G., \& YUdiTsKY, T. (1996). Naming times for the Snodgrass and Vanderwart pictures. Behavior Research Methods, Instruments, \& Computers, 28, 516-536.

VITKOVITCH, M., \& TYRRELL,L. (1995). Sources of disagreement in object naming. Quarterly Journal of Experimental Psychology, 48A 822-848.

\section{NOTES}

1. We were not aware of the work by Bonin et al. (2003) during the preparation of our study.

2. An attempt was made to code both participants and items with dummy variables. This involved using $10+45+328=383$ predictors, and it led our statistical program to drop many item predictors. Therefore this item coding was abandoned.

3 . There was no effect of the variable visual complexity during the familiarization phase, although it had an effect during the experimental phase. This point is discussed below, in the section devoted to this variable. 
APPENDIX

Mean Naming Latencies $(M)$, Standard Deviations $(S D)$, and Percentage of Correct Responses $(\%)$ in the Immediate Pronunciation Tasks for the 329 Items Used in the Analyses

\begin{tabular}{|c|c|c|c|c|c|c|}
\hline \multirow[b]{2}{*}{ No. } & \multirow{2}{*}{$\begin{array}{c}\text { No. } \\
(\mathrm{A} \& \mathrm{~F})\end{array}$} & \multirow[b]{2}{*}{ French } & \multirow[b]{2}{*}{ English } & \multicolumn{3}{|c|}{ Immediate Naming } \\
\hline & & & & $M$ & $S D$ & $\%$ \\
\hline 1 & 1 & accordéon & accordion & 841 & 287 & 89 \\
\hline 2 & 2 & gland & acorn & 961 & 224 & 65 \\
\hline 3 & 3 & avion & airplane & 671 & 161 & 98 \\
\hline 4 & 4 & crocodile & alligator & 815 & 258 & 96 \\
\hline 5 & 5 & ancre & anchor & 888 & 224 & 80 \\
\hline 6 & 6 & fourmi & ant & 993 & 234 & 89 \\
\hline 7 & 8 & enclume & anvil & 883 & 190 & 57 \\
\hline 8 & 9 & pomme & apple & 735 & 205 & 100 \\
\hline 9 & 11 & bras & arm & 856 & 196 & 96 \\
\hline 10 & 13 & flèche & arrow & 746 & 149 & 98 \\
\hline 11 & 14 & artichaut & artichoke & 941 & 279 & 65 \\
\hline 12 & 15 & cendrier & ashtray & 892 & 219 & 96 \\
\hline 13 & 16 & asperge & asparagus & 949 & 256 & 78 \\
\hline 14 & 17 & avocat & avocado & 935 & 212 & 74 \\
\hline 15 & 18 & hache & axe & 834 & 218 & 91 \\
\hline 16 & 19 & landau & baby carriage & 879 & 243 & 54 \\
\hline 17 & 20 & ballon & ball & 711 & 167 & 96 \\
\hline 18 & 21 & ballon & balloon & 675 & 153 & 98 \\
\hline 19 & 22 & banane & banana & 648 & 172 & 100 \\
\hline 20 & 24 & tonneau & barrel & 801 & 260 & 80 \\
\hline 21 & 26 & panier & basket & 766 & 255 & 98 \\
\hline 22 & 27 & chauve-souris & bat & 903 & 261 & 96 \\
\hline 23 & 28 & ours & bear & 793 & 162 & 98 \\
\hline 24 & 29 & lit & bed & 628 & 122 & 98 \\
\hline 25 & 30 & abeille & bee & 1,029 & 241 & 65 \\
\hline 26 & 32 & cloche & bell & 745 & 224 & 96 \\
\hline 27 & 33 & ceinture & belt & 720 & 159 & 98 \\
\hline 28 & 34 & banc & bench & 725 & 186 & 98 \\
\hline 29 & 35 & vélo & bicycle & 688 & 181 & 89 \\
\hline 30 & 36 & jumelles & binoculars & 847 & 308 & 85 \\
\hline 31 & 37 & oiseau & bird & 852 & 263 & 72 \\
\hline 32 & 38 & cage & bird cage & 857 & 183 & 93 \\
\hline 33 & 39 & nid & bird nest & 852 & 145 & 96 \\
\hline 34 & 40 & dirigeable & blimp & 1,222 & 226 & 41 \\
\hline 35 & 42 & livre & book & 640 & 140 & 93 \\
\hline 36 & 43 & botte & boot & 786 & 172 & 96 \\
\hline 37 & 44 & bouteille & bottle & 744 & 209 & 98 \\
\hline 38 & 45 & nœud & bow & 773 & 192 & 67 \\
\hline 39 & 46 & bol & bowl & 934 & 302 & 78 \\
\hline 40 & 47 & boîte & box & 905 & 264 & 80 \\
\hline 41 & 48 & cerveau & brain & 853 & 201 & 98 \\
\hline 42 & 49 & pain & bread & 794 & 191 & 61 \\
\hline 43 & 50 & balai & broom & 814 & 257 & 93 \\
\hline 44 & 51 & brosse & brush & 787 & 194 & 96 \\
\hline 45 & 52 & bison & buffalo & 1,089 & 261 & 61 \\
\hline 46 & 53 & bus & bus & 828 & 202 & 78 \\
\hline 47 & 54 & papillon & butterfly & 674 & 157 & 93 \\
\hline 48 & 55 & bouton & button & 910 & 252 & 87 \\
\hline 49 & 56 & cactus & cactus & 798 & 200 & 93 \\
\hline 50 & 57 & caddie & caddy & 846 & 199 & 46 \\
\hline 51 & 58 & gâteau & cake & 745 & 159 & 93 \\
\hline 52 & 59 & chameau & camel & 932 & 306 & 72 \\
\hline 53 & 62 & bougie & candle & 702 & 142 & 91 \\
\hline 54 & 63 & canon & cannon & 798 & 160 & 96 \\
\hline 55 & 64 & casquette & cap & 795 & 189 & 93 \\
\hline 56 & 65 & voiture & car & 690 & 175 & 93 \\
\hline 57 & 66 & carotte & carrot & 636 & 130 & 98 \\
\hline 58 & 67 & chat & cat & 636 & 125 & 100 \\
\hline 59 & 68 & chenille & caterpillar & 965 & 316 & 74 \\
\hline
\end{tabular}


APPENDIX (Continued)

\begin{tabular}{|c|c|c|c|c|c|c|}
\hline \multirow[b]{2}{*}{ No. } & \multirow{2}{*}{$\begin{array}{c}\text { No. } \\
\text { (A\&F) }\end{array}$} & \multirow[b]{2}{*}{ French } & \multirow[b]{2}{*}{ English } & \multicolumn{3}{|c|}{ Immediate Naming } \\
\hline & & & & $M$ & $S D$ & $\%$ \\
\hline 60 & 69 & céleri & celery & 1,109 & 210 & $\overline{41}$ \\
\hline 61 & 70 & chaîne & chain & 756 & 187 & 91 \\
\hline 62 & 71 & chaise & chair & 608 & 131 & 98 \\
\hline 63 & 73 & cerise & cherry & 775 & 160 & 98 \\
\hline 64 & 74 & malle & chest & 1,004 & 268 & 48 \\
\hline 65 & 75 & poule & chicken & 925 & 265 & 87 \\
\hline 66 & 76 & cheminée & chimney & 794 & 173 & 96 \\
\hline 67 & 78 & église & church & 724 & 139 & 96 \\
\hline 68 & 79 & cigare & cigar & 984 & 215 & 96 \\
\hline 69 & 80 & cigarette & cigarette & 854 & 156 & 98 \\
\hline 70 & 81 & horloge & clock & 891 & 244 & 78 \\
\hline 71 & 84 & nuage & cloud & 953 & 276 & 87 \\
\hline 72 & 85 & clown & clown & 679 & 87 & 96 \\
\hline 73 & 86 & manteau & coat & 928 & 289 & 70 \\
\hline 74 & 88 & passoire & colander & 923 & 296 & 74 \\
\hline 75 & 89 & peigne & comb & 760 & 194 & 98 \\
\hline 76 & 90 & boussole & compass & 1,025 & 194 & 80 \\
\hline 77 & 91 & maïs & corn & 842 & 152 & 93 \\
\hline 78 & 92 & canapé & couch & 878 & 250 & 65 \\
\hline 79 & 93 & vache & cow & 858 & 171 & 89 \\
\hline 80 & 94 & crabe & crab & 921 & 269 & 87 \\
\hline 81 & 95 & couronne & crown & 830 & 164 & 96 \\
\hline 82 & 96 & tasse & cup & 730 & 161 & 98 \\
\hline 83 & 98 & fléchette & dart & 930 & 167 & 72 \\
\hline 84 & 99 & cerf & deer & 1,115 & 290 & 72 \\
\hline 85 & 100 & bureau & desk & 965 & 236 & 72 \\
\hline 86 & 101 & dinosaure & dinosaur & 1,078 & 275 & 96 \\
\hline 87 & 102 & chien & $\operatorname{dog}$ & 689 & 152 & 100 \\
\hline 88 & 103 & niche & doghouse & 873 & 246 & 80 \\
\hline 89 & 104 & poupée & doll & 782 & 172 & 98 \\
\hline 90 & 105 & dauphin & dolphin & 724 & 178 & 98 \\
\hline 91 & 106 & âne & donkey & 858 & 251 & 100 \\
\hline 92 & 107 & porte & door & 703 & 181 & 91 \\
\hline 93 & 108 & poignée & doorknob & 1,179 & 232 & 72 \\
\hline 94 & 109 & libellule & dragonfly & 932 & 273 & 85 \\
\hline 95 & 110 & robe & dress & 866 & 262 & 100 \\
\hline 96 & 111 & commode & dresser & 984 & 238 & 76 \\
\hline 97 & 112 & tambour & drum & 891 & 260 & 96 \\
\hline 98 & 113 & canard & duck & 813 & 180 & 93 \\
\hline 99 & 115 & aigle & eagle & 1,027 & 280 & 87 \\
\hline 100 & 116 & oreille & ear & 631 & 96 & 98 \\
\hline 101 & 118 & anguille & eel & 1,161 & 234 & 67 \\
\hline 102 & 119 & éléphant & elephant & 633 & 103 & 100 \\
\hline 103 & 120 & enveloppe & envelope & 733 & 220 & 80 \\
\hline 104 & 121 & oeil & eye & 658 & 165 & 98 \\
\hline 105 & 122 & éventail & fan & 948 & 264 & 70 \\
\hline 106 & 123 & robinet & faucet & 864 & 230 & 93 \\
\hline 107 & 124 & plume & feather & 762 & 188 & 98 \\
\hline 108 & 125 & barrière & fence & 783 & 200 & 87 \\
\hline 109 & 126 & fougère & fern & 984 & 260 & 78 \\
\hline 110 & 128 & doigt & finger & 725 & 242 & 87 \\
\hline 111 & 129 & poisson & fish & 672 & 133 & 96 \\
\hline 112 & 130 & aquarium & fishbowl & 1,060 & 229 & 61 \\
\hline 113 & 131 & hameçon & fishhook & 1,082 & 241 & 54 \\
\hline 114 & 134 & drapeau & flag & 706 & 122 & 91 \\
\hline 115 & 135 & flamand & flamingo & 1,040 & 274 & 41 \\
\hline 116 & 137 & fleur & flower & 746 & 219 & 100 \\
\hline 117 & 139 & mouche & fly & 1,003 & 225 & 87 \\
\hline 118 & 140 & pied & foot & 646 & 143 & 100 \\
\hline 119 & 141 & fourchette & fork & 747 & 190 & 100 \\
\hline 120 & 142 & renard & fox & 976 & 318 & 91 \\
\hline
\end{tabular}


APPENDIX (Continued)

\begin{tabular}{|c|c|c|c|c|c|c|}
\hline \multirow[b]{2}{*}{ No. } & \multirow{2}{*}{$\begin{array}{c}\text { No. } \\
(\mathrm{A} \& \mathrm{~F})\end{array}$} & \multirow[b]{2}{*}{ French } & \multirow[b]{2}{*}{ English } & \multicolumn{3}{|c|}{ Immediate Naming } \\
\hline & & & & $M$ & $S D$ & $\%$ \\
\hline$\overline{121}$ & 143 & croissant & French croissant & 735 & 107 & $\overline{100}$ \\
\hline 122 & 145 & grenouille & frog & 785 & 273 & 80 \\
\hline 123 & 146 & poêle & frying pan & 968 & 206 & 70 \\
\hline 124 & 147 & entonnoir & funnel & 855 & 295 & 93 \\
\hline 125 & 148 & poubelle & garbage can & 759 & 178 & 93 \\
\hline 126 & 149 & girafe & giraffe & 684 & 168 & 100 \\
\hline 127 & 150 & verre & glass & 706 & 194 & 96 \\
\hline 128 & 151 & lunettes & glasses & 632 & 132 & 93 \\
\hline 129 & 152 & mappemonde & globe & 891 & 218 & 65 \\
\hline 130 & 153 & gant & glove & 747 & 118 & 96 \\
\hline 131 & 154 & chèvre & goat & 986 & 288 & 76 \\
\hline 132 & 156 & gorille & gorilla & 934 & 267 & 83 \\
\hline 133 & 157 & raisin & grapes & 840 & 269 & 91 \\
\hline 134 & 158 & sauterelle & grasshopper & 1,045 & 263 & 50 \\
\hline 135 & 159 & barbecue & grill & 1,003 & 208 & 65 \\
\hline 136 & 160 & guitare & guitar & 727 & 188 & 100 \\
\hline 137 & 161 & pistolet & gun & 829 & 193 & 80 \\
\hline 138 & 162 & cheveux & hair & 899 & 204 & 93 \\
\hline 139 & 164 & marteau & hammer & 919 & 273 & 96 \\
\hline 140 & 165 & hamac & hammock & 1,042 & 231 & 89 \\
\hline 141 & 166 & main & hand & 631 & 138 & 100 \\
\hline 142 & 167 & cintre & hanger & 774 & 196 & 89 \\
\hline 143 & 168 & harmonica & harmonica & 931 & 258 & 76 \\
\hline 144 & 169 & harpe & harp & 779 & 158 & 89 \\
\hline 145 & 170 & chapeau & hat & 621 & 128 & 100 \\
\hline 146 & 172 & cœur & heart & 608 & 104 & 100 \\
\hline 147 & 173 & hélicoptère & helicopter & 694 & 176 & 100 \\
\hline 148 & 174 & casque & helmet & 702 & 141 & 98 \\
\hline 149 & 175 & hippopotame & hippopotamus & 904 & 242 & 83 \\
\hline 150 & 177 & cheval & horse & 692 & 173 & 98 \\
\hline 151 & 179 & maison & house & 774 & 236 & 93 \\
\hline 152 & 180 & hyène & hyena & 1,087 & 272 & 80 \\
\hline 153 & 181 & igloo & igloo & 732 & 139 & 100 \\
\hline 154 & 183 & veste & jacket & 1,042 & 325 & 57 \\
\hline 155 & 184 & bocal & jar & 984 & 220 & 67 \\
\hline 156 & 185 & méduse & jellyfish & 1,057 & 308 & 57 \\
\hline 157 & 186 & kangourou & kangaroo & 790 & 227 & 93 \\
\hline 158 & 187 & bouilloire & kettle & 1,175 & 296 & 41 \\
\hline 159 & 188 & clef & key & 660 & 115 & 98 \\
\hline 160 & 189 & cerf-volant & kite & 800 & 185 & 93 \\
\hline 161 & 190 & couteau & knife & 728 & 215 & 98 \\
\hline 162 & 191 & koala & koala & 878 & 198 & 93 \\
\hline 163 & 192 & échelle & ladder & 699 & 191 & 96 \\
\hline 164 & 193 & louche & ladle & 911 & 258 & 89 \\
\hline 165 & 194 & coccinelle & ladybug & 905 & 230 & 85 \\
\hline 166 & 195 & agneau & lamb & 1,050 & 347 & 41 \\
\hline 167 & 196 & lampe & lamp & 701 & 145 & 93 \\
\hline 168 & 197 & tondeuse & lawnmower & 1,065 & 299 & 67 \\
\hline 169 & 198 & feuille & leaf & 913 & 272 & 98 \\
\hline 170 & 199 & jambe & leg & 928 & 244 & 87 \\
\hline 171 & 200 & citron & lemon & 717 & 198 & 100 \\
\hline 172 & 201 & léopard & leopard & 1,033 & 267 & 52 \\
\hline 173 & 203 & ampoule & light bulb & 734 & 151 & 80 \\
\hline 174 & 204 & interrupteur & light switch & 1,021 & 267 & 78 \\
\hline 175 & 205 & lion & lion & 805 & 196 & 96 \\
\hline 176 & 206 & bouche & lips & 728 & 252 & 83 \\
\hline 177 & 208 & lézard & lizard & 867 & 243 & 87 \\
\hline 178 & 209 & lama & llama & 1,006 & 254 & 83 \\
\hline 179 & 211 & cadenas & lock & 898 & 217 & 91 \\
\hline 180 & 212 & $\mathrm{~b}^{\circ}$ ches & $\log s$ & 1,163 & 318 & 50 \\
\hline 181 & 213 & poumons & lungs & 1,075 & 273 & 93 \\
\hline
\end{tabular}


APPENDIX (Continued)

\begin{tabular}{|c|c|c|c|c|c|c|}
\hline \multirow[b]{2}{*}{ No. } & \multirow{2}{*}{$\begin{array}{c}\text { No. } \\
\text { (A\&F) }\end{array}$} & \multirow[b]{2}{*}{ French } & \multirow[b]{2}{*}{ English } & \multicolumn{3}{|c|}{ Immediate Naming } \\
\hline & & & & $M$ & $S D$ & $\%$ \\
\hline 182 & 214 & maracas & maracas & 924 & 232 & 63 \\
\hline 183 & 215 & microscope & microscope & 1,081 & 228 & 61 \\
\hline 184 & 216 & moufle & mitten & 910 & 176 & 46 \\
\hline 185 & 217 & singe & monkey & 831 & 234 & 93 \\
\hline 186 & 218 & lune & moon & 729 & 203 & 98 \\
\hline 187 & 219 & élan & moose & 1,089 & 277 & 57 \\
\hline 188 & 220 & moto & motorcycle & 789 & 227 & 93 \\
\hline 189 & 221 & montagne & mountain & 872 & 228 & 96 \\
\hline 190 & 222 & souris & mouse & 866 & 215 & 85 \\
\hline 191 & 223 & champignon & mushroom & 670 & 103 & 96 \\
\hline 192 & 224 & clou & nail & 958 & 258 & 89 \\
\hline 193 & 225 & lime & nail file & 978 & 307 & 78 \\
\hline 194 & 226 & collier & necklace & 740 & 208 & 100 \\
\hline 195 & 227 & aiguille & needle & 947 & 262 & 80 \\
\hline 196 & 228 & nez & nose & 671 & 100 & 98 \\
\hline 197 & 229 & écrou & nut & 941 & 288 & 48 \\
\hline 198 & 230 & poulpe & octopus & 1,177 & 288 & 48 \\
\hline 199 & 231 & oignon & onion & 980 & 288 & 87 \\
\hline 200 & 232 & orange & orange & 944 & 271 & 85 \\
\hline 201 & 233 & autruche & ostrich & 922 & 264 & 70 \\
\hline 202 & 234 & hibou & owl & 855 & 257 & 96 \\
\hline 203 & 236 & pinceau & paintbrush & 766 & 209 & 93 \\
\hline 204 & 237 & palmier & palm tree & 751 & 157 & 96 \\
\hline 205 & 239 & pantalon & pants & 659 & 135 & 100 \\
\hline 206 & 240 & parachute & parachute & 1,201 & 295 & 78 \\
\hline 207 & 241 & perroquet & parrot & 1,033 & 294 & 78 \\
\hline 208 & 242 & pêche & peach & 1,118 & 259 & 52 \\
\hline 209 & 243 & paon & peacock & 962 & 245 & 89 \\
\hline 210 & 244 & cacahouète & peanut & 795 & 206 & 93 \\
\hline 211 & 245 & poire & pear & 722 & 212 & 93 \\
\hline 212 & 247 & pélican & pelican & 995 & 309 & 65 \\
\hline 213 & 248 & stylo & pen & 868 & 215 & 87 \\
\hline 214 & 249 & crayon & pencil & 668 & 160 & 96 \\
\hline 215 & 250 & pingouin & penguin & 855 & 257 & 96 \\
\hline 216 & 251 & poivron & pepper & 1,029 & 247 & 72 \\
\hline 217 & 252 & piano & piano & 743 & 163 & 93 \\
\hline 218 & 253 & tableau & picture & 761 & 179 & 91 \\
\hline 219 & 254 & cochon & pig & 883 & 217 & 100 \\
\hline 220 & 255 & flipper & pinball machine & 1,097 & 219 & 70 \\
\hline 221 & 256 & ananas & pineapple & 732 & 172 & 100 \\
\hline 222 & 257 & pipe & pipe & 689 & 146 & 96 \\
\hline 223 & 260 & pince & pliers & 1,034 & 256 & 74 \\
\hline 224 & 261 & prise & plug & 935 & 250 & 87 \\
\hline 225 & 262 & sac & pocketbook & 800 & 230 & 78 \\
\hline 226 & 263 & casserole & pot & 913 & 290 & 91 \\
\hline 227 & 264 & pomme de terre & potato & 1,013 & 286 & 43 \\
\hline 228 & 265 & hélice & propeller & 842 & 261 & 96 \\
\hline 229 & 266 & citrouille & pumpkin & 890 & 269 & 72 \\
\hline 230 & 267 & pyramide & pyramid & 840 & 201 & 100 \\
\hline 231 & 268 & lapin & rabbit & 638 & 141 & 100 \\
\hline 232 & 270 & râteau & rake & 867 & 262 & 96 \\
\hline 233 & 271 & rat & rat & 857 & 185 & 80 \\
\hline 234 & 272 & raie & ray & 1,111 & 311 & 63 \\
\hline 235 & 273 & tourne-disque & record player & 916 & 244 & 85 \\
\hline 236 & 275 & rhinocéros & rhinoceros & 842 & 218 & 91 \\
\hline 237 & 276 & bague & ring & 875 & 216 & 96 \\
\hline 238 & 277 & fusée & rocket & 787 & 159 & 96 \\
\hline 239 & 280 & $\operatorname{coq}$ & rooster & 854 & 226 & 78 \\
\hline 240 & 281 & corde & rope & 836 & 254 & 98 \\
\hline 241 & 282 & règle & ruler & 790 & 236 & 93 \\
\hline 242 & 283 & selle & saddle & 898 & 227 & 91 \\
\hline
\end{tabular}


APPENDIX (Continued)

\begin{tabular}{|c|c|c|c|c|c|c|}
\hline \multirow[b]{2}{*}{ No. } & \multirow{2}{*}{$\begin{array}{c}\text { No. } \\
(\mathrm{A} \& \mathrm{~F})\end{array}$} & \multirow[b]{2}{*}{ French } & \multirow[b]{2}{*}{ English } & \multicolumn{3}{|c|}{ Immediate Naming } \\
\hline & & & & $M$ & $S D$ & $\%$ \\
\hline 243 & 284 & coffre-fort & safe & 1,067 & 213 & $\overline{70}$ \\
\hline 244 & 285 & voilier & sailboat & 902 & 220 & 46 \\
\hline 245 & 286 & salière & salt shaker & 1,053 & 293 & 52 \\
\hline 246 & 287 & sandwich & sandwich & 837 & 209 & 98 \\
\hline 247 & 288 & scie & saw & 755 & 215 & 91 \\
\hline 248 & 289 & saxophone & saxophone & 1,095 & 319 & 76 \\
\hline 249 & 290 & balance & scale & 745 & 134 & 100 \\
\hline 250 & 291 & ciseau & scissors & 673 & 151 & 100 \\
\hline 251 & 292 & pelle & spatula & 1,074 & 294 & 54 \\
\hline 252 & 293 & scorpion & scorpion & 1,053 & 292 & 74 \\
\hline 253 & 294 & vis & screw & 945 & 242 & 83 \\
\hline 254 & 295 & tournevis & screwdriver & 864 & 255 & 83 \\
\hline 255 & 296 & hippocampe & sea horse & 939 & 302 & 70 \\
\hline 256 & 297 & phoque & seal & 1,138 & 329 & 63 \\
\hline 257 & 298 & requin & shark & 881 & 267 & 91 \\
\hline 258 & 299 & mouton & sheep & 1,062 & 338 & 67 \\
\hline 259 & 300 & chemise & shirt & 942 & 277 & 85 \\
\hline 260 & 301 & chaussure & shoe & 649 & 123 & 89 \\
\hline 261 & 302 & douche & shower head & 876 & 210 & 91 \\
\hline 262 & 303 & squelette & skeleton & 736 & 150 & 98 \\
\hline 263 & 304 & ski & ski & 854 & 199 & 93 \\
\hline 264 & 305 & jupe & skirt & 897 & 266 & 83 \\
\hline 265 & 306 & crâne & skull & 909 & 285 & 80 \\
\hline 266 & 307 & putois & skunk & 1,061 & 308 & 43 \\
\hline 267 & 308 & luge & sled & 822 & 234 & 91 \\
\hline 268 & 309 & escargot & snail & 734 & 188 & 98 \\
\hline 269 & 310 & serpent & snake & 697 & 157 & 98 \\
\hline 270 & 312 & chaussette & sock & 644 & 132 & 98 \\
\hline 271 & 314 & araignée & spider & 857 & 192 & 96 \\
\hline 272 & 316 & rouet & spinning wheel & 993 & 238 & 46 \\
\hline 273 & 318 & cuillère & spoon & 722 & 208 & 96 \\
\hline 274 & 320 & écureuil & squirrel & 794 & 197 & 93 \\
\hline 275 & 321 & étoile & star & 639 & 177 & 98 \\
\hline 276 & 323 & stéthoscope & stethoscope & 1,080 & 228 & 74 \\
\hline 277 & 324 & tabouret & stool & 779 & 207 & 93 \\
\hline 278 & 325 & cuisinière & stove & 1,129 & 299 & 57 \\
\hline 279 & 326 & fraise & strawberry & 762 & 243 & 89 \\
\hline 280 & 327 & valise & suitcase & 733 & 182 & 98 \\
\hline 281 & 328 & soleil & sun & 648 & 191 & 100 \\
\hline 282 & 329 & cygne & swan & 786 & 220 & 93 \\
\hline 283 & 332 & balançoire & swing & 799 & 188 & 98 \\
\hline 284 & 333 & espadon & swordfish & 952 & 308 & 41 \\
\hline 285 & 334 & seringue & syringe & 819 & 157 & 93 \\
\hline 286 & 335 & table & table & 667 & 132 & 98 \\
\hline 287 & 337 & téléphone & telephone & 620 & 104 & 100 \\
\hline 288 & 339 & télévision & television & 760 & 175 & 70 \\
\hline 289 & 341 & thermomètre & thermometer & 762 & 218 & 89 \\
\hline 290 & 342 & thermos & thermos & 1,071 & 315 & 57 \\
\hline 291 & 344 & pouce & thumb & 896 & 204 & 74 \\
\hline 292 & 345 & cravate & tie & 757 & 253 & 93 \\
\hline 293 & 346 & tigre & tiger & 880 & 254 & 89 \\
\hline 294 & 347 & pneu & tire & 906 & 239 & 65 \\
\hline 295 & 348 & grille-pain & toaster & 1,093 & 339 & 54 \\
\hline 296 & 349 & orteil & toe & 1,155 & 189 & 48 \\
\hline 297 & 350 & tomate & tomato & 829 & 240 & 93 \\
\hline 298 & 352 & toupie & top & 802 & 162 & 91 \\
\hline 299 & 353 & totem & totem pole & 912 & 274 & 85 \\
\hline 300 & 355 & tracteur & tractor & 799 & 241 & 96 \\
\hline 301 & 356 & feu & traffic light & 918 & 223 & 80 \\
\hline 302 & 357 & train & train & 785 & 237 & 93 \\
\hline 303 & 358 & oeuf & tram car & 1,246 & 186 & 41 \\
\hline
\end{tabular}


APPENDIX (Continued)

\begin{tabular}{|c|c|c|c|c|c|c|}
\hline \multirow[b]{2}{*}{ No. } & \multirow{2}{*}{$\begin{array}{c}\text { No. } \\
\text { (A\&F) }\end{array}$} & \multirow[b]{2}{*}{ French } & \multirow[b]{2}{*}{ English } & \multicolumn{3}{|c|}{ Immediate Naming } \\
\hline & & & & $M$ & $S D$ & $\%$ \\
\hline 304 & 359 & arbre & tree & 715 & 228 & 100 \\
\hline 305 & 360 & camion & truck & 704 & 121 & 100 \\
\hline 306 & 361 & trompette & trumpet & 799 & 231 & 93 \\
\hline 307 & 362 & dindon & turkey & 1,058 & 273 & 50 \\
\hline 308 & 363 & tortue & turtle & 697 & 213 & 100 \\
\hline 309 & 364 & parapluie & umbrella & 662 & 155 & 100 \\
\hline 310 & 365 & vase & vase & 778 & 177 & 100 \\
\hline 311 & 366 & gilet & vest & 981 & 235 & 57 \\
\hline 312 & 367 & violon & violin & 967 & 274 & 72 \\
\hline 313 & 368 & vautour & vulture & 1,135 & 314 & 43 \\
\hline 314 & 370 & morse & walrus & 1,064 & 230 & 52 \\
\hline 315 & 372 & montre & watch & 684 & 162 & 96 \\
\hline 316 & 373 & arrosoir & watering can & 755 & 195 & 96 \\
\hline 317 & 374 & pastèque & watermelon & 891 & 219 & 85 \\
\hline 318 & 375 & girouette & weather vane & 1,108 & 251 & 59 \\
\hline 319 & 376 & puits & well & 922 & 287 & 91 \\
\hline 320 & 377 & baleine & whale & 985 & 265 & 87 \\
\hline 321 & 378 & roue & wheel & 826 & 307 & 93 \\
\hline 322 & 379 & fouet & whip & 1,074 & 277 & 76 \\
\hline 323 & 380 & sifflet & whistle & 766 & 164 & 96 \\
\hline 324 & 381 & moulin & windmill & 832 & 229 & 83 \\
\hline 325 & 382 & fenêtre & window & 904 & 195 & 93 \\
\hline 326 & 383 & loup & wine glass & 823 & 191 & 93 \\
\hline 327 & 385 & clé & wrench & 1,138 & 295 & 48 \\
\hline 328 & 386 & уо-уо & yo-yo & 1,008 & 228 & 89 \\
\hline 329 & 387 & zèbre & zebra & 791 & 185 & 96 \\
\hline
\end{tabular}

(Manuscript received February 19, 2002;

revision accepted for publication May 28, 2003.) 